\title{
CUIDADO COLETIVIZADO: ORDENAMENTO TERRITORIAL E O DIREITO À CIDADE SAUDÁVEL FRENTE À CRISE SANITÁRIA
}

\section{Resumo}

\section{Érica Pinheiro de Albuquerque Leal ${ }^{1}$}

O presente artigo aborda a gestão do cuidado coletivo na Atenção Básica à Saúde (ABS), através do estudo do ordenamento territorial enquanto adensamento dos processos de produção, urbanização e das relações sociais na atual crise sanitária. Diante disso, em detrimento da reprodução das interações sociais que não serviam de arquétipo para as políticas públicas, a proposta é de analisar o alcance ao direito à cidade com a consecução de territórios saudáveis, por meio da aplicação de gestão governamental participativa com ações interseccionais que surgiram desde a reforma sanitária brasileira, por meio da metodologia de pesquisa bibliográfica.

Palavras-chave: Interações sociais; Ordenação territorial; Crise sanitária; Atenção Básica à Saúde; Cidade saudável.

\section{COLLECTIVE CARE: TERRITORIAL ORDINATION AND THE RIGHT TO THE HEALTH CITY IN FRONT OF THE SANITARY CRISIS}

\begin{abstract}
This article addresses the management of collective care in Primary Health Care (ABS), through the study of territorial ordering as a densification of production, urbanization and social relations processes in the current health crisis. Therefore, to the detriment of the reproduction of social interactions that did not serve as an archetype for public policies, the proposal is to analyze the reach of the right to the city with the achievement of healthy territories, through the application of participatory government management with intersectional actions that emerged since the Brazilian sanitary reform, through bibliographic research methodology.
\end{abstract}

Keywords/Palabras-claves/Mots-clés: Social interactions; Territorial ordering; Sanitary crisis; Primary Health Care; Healthy city.

\section{INTRODUÇÃO}

A crise sanitária na realidade brasileira não é inovação e demonstrou-se significativamente com o acirramento das disparidades socioeconômicas frente as diversas formas de uso, ocupação do território e do fracionamento do sistema de saúde brasileiro. Tais desigualdades tiveram o efeito resultante na reprodução capitalista de modalidades

\footnotetext{
${ }^{1}$ Graduada em Direito pela Universidade Federal do Pará - UFPA (2019). Pós-graduanda em Direito Civil na Pontifícia Universidade Católica de Minas Gerais - PUC/MG. Mestranda no Programa de Pós-Graduação em Direito da Universidade Federal do Pará, na linha de pesquisa Diretos Humanos e Meio Ambiente. E-mail: ericaalbuquerqueleal@outlook.com.
} 
assistenciais dessemelhantes as classes sociais, representando a escassez de acesso unificado à saúde e ilustrando quadros de exclusão dos economicamente desfavorecidos.

Nesse sentido, a Política Nacional de Atenção Básica (PNAB) constituída a partir das vivências repartida por todos os incumbidos pelo desdobramento e estruturação do Sistema Único de Saúde (SUS) não concretizam as metas estipuladas nas diretrizes quanto a universalidade, a equidade e a integralidade da atenção aos cidadãos a serem atendidos.

Sob tal perspectiva, o planejamento de atendimento tem sido pauta de debates acerca da eleição do cuidado coletivo como ação advinda do ordenamento do território, de promoção da saúde e do controle e avaliação por parte da sociedade (ARANTES; CAMACHO; RIBEIRO; VERARDINO, 2014).

Diante disso, o processo histórico de espoliação urbana e de ocupação irregular do solo agregará para a análise tanto fático-territorial quanto reprodutiva da estratificação social quando instaurada a lógica de apropriação do tempo e do espaço capitalista (KOWARICK, 1980). De modo a apresentar repercussões no gerenciamento da atenção básica nas cidades, em vista das relações territoriais com o espaço urbano não se restringirem apenas ao solo, mas ao processo de interação social para ocupá-lo e integrá-lo (SANTOS; SILVEIRA, 2001).

À vista de tal argumentação, o presente artigo analisa a interdependência entre a materialidade do solo, como também alberga a vontade humana, a forma de reprodução dos trabalhos, das políticas e da gestão desse "território vivo", no qual os interesses são geridos de forma estratégica para alcançar um fim.

Portanto, preocupa-se em responder a indagação acerca do direito à cidade saudável a partir do enfrentamento da crise sanitária perante o reflexo das relações sociais de produção e urbanização, em que pese o termo urbano estar para além dos limites citadinos territoriais.

Nesse diapasão, esclarece a luta pelo direito à saúde como enfrentamento por vias democráticas e o fortalecimento de espaços táticos assistenciais que alcancem as necessidades dos cidadãos com uma concepção ampliada de saúde, reconhecida como direito social para todos, com a valorização da participação social para a promoção do alcance das cidades saudáveis.

E, para o desenvolvimento do estudo foi implementada a metodologia de pesquisa bibliográfica, com o levantamento dos materiais já publicados referentes as temáticas abordadas no artigo, e a fundamentação teórica utilizada foi de revisão de literatura, com a análise das produções traçando uma linha de raciocínio e estruturação conceitual para desenvolvimento da pesquisa. 


\section{REPRODUÇÃO DAS RELAÇÕES SOCIAIS NA ESTRUTURAÇÃO DO ORDENAMENTO TERRITORIAL}

O ordenamento territorial e a formação socioespacial encontram a semântica fincada na materialidade das relações sociais, na ação dos indivíduos como principal dimensão da ocupação do solo. Dito de outra maneira, na dissertação da obra acerca da produção do espaço do filósofo francês foi enfatizado que o desenvolvimento do espaço social constitui como produto das interações humanas de reprodução e de produção, resguardando um suporte para que essas reverberem na interação com o território (LEFEBVRE, 2020).

Dessa forma, repercute o reconhecimento do conceito de espaço social como detentor do espaço físico, cujo sujeito enquanto ator de uma vida social o transforma com a aplicação do trabalho. Isto é, a natureza abastece os indivíduos de recursos para o desenvolvimento da atividade produtiva, de modo a dinamizar o espaço social através das relações de reprodução, que são conhecidas pela natureza biológica; e as relações de produção e organização do labor, a composição do trabalho de forma hierarquizada (LEFEBVRE, 2020).

Com efeito, o arranjo do espaço acaba por sucumbir aos elementos das práticas sociais reproduzidas pelos indivíduos, às representações empíricas do espaço e à posição de representação do território enquanto vivência dos sujeitos.

Nessa linha de raciocínio, o modo de produção de uma sociedade será determinante para a formação do espaço e para a posterior aplicação de um ordenamento territorial. Nesse diapasão, Milton Santos versa que o espaço geográfico é "formado por um conjunto indissociável, solidário e também contraditório, de sistemas de objetos e sistemas de ações, não considerados isoladamente, mas como o quadro único no qual a história se dá" (SANTOS, 1997, p. 51).

Sendo assim, a forma de apropriação do território é concomitante o resultado das interações sociais, constituindo "um conjunto de meios instrumentais e sociais, com os quais o homem realiza sua vida, produz e, ao mesmo tempo, cria espaço.” (SANTOS, 2002, p. 29). Dessa maneira, a compreensão da natureza do espaço associada a evolução das técnicas configura a possibilidade de união da intrínseca relação do indivíduo com o território e do indivíduo com ele mesmo, produzindo assim o espaço geográfico.

$\mathrm{Na}$ realidade brasileira, as raízes de reprodução das interações sociais no espaço geográfico são marcantes, principalmente pela trajetória histórica de colonialismo 
escravocrata, que enredou na formação do primeiro tecido social subordinado a autoridade dos que concentravam renda e propriedade.

Consequentemente, a estrutura hierárquica dos ambientes políticos e sociais "reforçam também as posições e situações dos diferentes agentes sociais, na medida em que o uso contínuo desse espaço hierarquizado também é suficiente para produzir suas próprias hierarquias" (MELAZZO; GUIMARÃES, 2010, p. 25).

Destarte, a análise de ocupação territorial não deve se desvencilhar do estudo acerca da interação social, pois o elemento vivo de instauração das dessimetrias socioeconômicas está imbrincado com a forma de se apropriar do solo, de modo que "há desigualdades sociais que são, em primeiro lugar, desigualdades territoriais, porque derivam do lugar onde cada qual se encontra" (SANTOS, 1988, p. 123).

Acerca disso, a análise de crescimento econômico nas metrópoles do Brasil representa a rede de relações sociais que impuseram aos cidadãos as problemáticas de pauperização nas relações de trabalho, revelando o desnivelamento da distribuição de renda, da forma de ocupação do solo.

A origem dessa desigualdade inicia-se com a intensificação do processo de industrialização paralelo a valorização dos terrenos fabris e residenciais nos centros urbanos, que afugentaram as anteriores estruturas de vilas operárias. De modo que a questão da moradia para os trabalhadores passa a ser revolvida pelas relações econômicas do mercado imobiliário. (KOWARICK, 1993).

Frente a especulação mobiliária, os fluxos migratórios da classe trabalhadora foram se distanciando dos centros, carentes de infraestrutura e caracterizados pelas ocupações desordenadas do solo. Ao contrário do que deveria ter sido feito, o poder público só se mostrou atuante quando o desenho urbano já estava parcialmente formado e subjugado ao fluxo das ocupações dos particulares e da dinâmica valoração-especulação.

Dentro desse contexto, a força de trabalho sujeitava-se a fadiga desencadeada pela engrenagem econômica que não fora controlada pelo estado e sim facilitada mais uma vez pela especulação imobiliária no melhoramento da malha viária, que valorizava preços de terrenos de zonas específicas com processos de desapropriação realizados pelo estado (KOWARICK, 1993).

Essa configuração espacial afastava ainda mais os grupos pobres das localidades valorizadas, em consequência das exigências impostas em relação as custas tributárias pelo 
poder público serem intangíveis para a parcela que constituía a mão-de-obra da futura metrópole.

E, é nesse cenário que as multinacionais entram para drenar de forma vertiginosa para o exterior os recursos investidos com as ideias do período repressivo de abertura econômica, devido a ausência de atuação firme no espaço político para preparar o ambiente econômico interno para essa exploração sem retorno de aplicação. Comprovando os prospectos de Henri Lefebvre (2008) de que as cidades estavam servindo de instrumento para o mercado, sacrificando o povo ao processo de espoliação urbana (KOWARICK, 1993).

Tal movimentação filtrava os grupos sociais frente a ocupação de determinadas áreas, em que há o deslocamento das camadas mais pobres e desfavorecidas de poderio político para as localidades mais distantes do centro, instituindo o processo de gentrificação (MENDES, 2011). Diante disso, as camadas populares não detinham os acessos aos serviços de consumo coletivo, pois o ordenamento territorial não era completo.

E, o Brasil reproduzia mais uma vez a figura da fragmentação urbana advinda do processo de globalização econômico e social, que desponta os níveis de desigualdade social e planeja a ocupação do território ao bel prazer do capital (BAUMAN, 2010). Portanto, a ausência de políticas sociais para ordenar a ocupação do território com visão intersetorial impulsionou o processo de encurtamento da dualidade espaço e tempo.

Na qual David Harvey (2005) tratará que o aumento da inserção do capital gera o crescimento direto do consumo e, consequentemente, da exploração dos trabalhadores. Esses que terão que ocupar e usufruir do território de forma diferenciada e muita das vezes precária, em detrimento da pauperização da força de trabalho. Logo, resta evidente que o território permeia e projeta as relações de poder que nele são disseminadas, constituindo espaços hierarquizados (MORAES, 2005).

Desta forma, o filosofo e sociólogo francês assevera que a crise da cidade é mundial contudo, "as causas práticas e as razões ideológicas dessa crise variam segundo os regimes políticos, segundo as sociedades e mesmo segundo os países em questão" (LEFEBVRE, 2001, p.74). Em vista disso, a questão socioeconômica nos territórios representa:

onde é o processo de reprodução do capital que indicará os modos de ocupação do espaço pela sociedade. [...] Ou seja, a acumulação capitalista é que determina a forma de produção e transformação do espaço construído. Formas de provisão de habitação, processos espaciais específicos6 como a suburbanização e metropolização de transformação do território que tendem a se estabilizar em ciclos históricos específicos tem sua lógica de 
transformação definida pelo regime de acumulação. (COUTINHO, 2011, p. 101)

Assim, fica compreendido que as problemáticas não se restringem ao aspecto local, devido o processo de urbanização se refletir sobre a forma de reprodução do capital no espaço nacional. À vista disso, subsiste o empenho de estruturar um planejamento interseccional e integrado, que reflita em todos os âmbitos e esferas que são marcadas pela segregação social e pelo inacesso da população alijada apenas a classe explorada e não detentora de voz nas interfaces local, regional e nacional.

\section{REFORMA SANITÁRIA DO SISTEMA DE SAÚDE BRASILEIRO E O POSTERIOR ACIRRAMENTO DA CRISE SANITÁRIA}

Nesse diapasão, o sistema de saúde público enquadra-se na esfera que refletiu por muitos anos os interesses sociais e políticos que legitimavam as formas de ocupação e ordenamento territorial, de modo que antes da instauração da reforma sanitária, apresentava a dualidade de uma sistemática de medicina previdenciária e de outro âmbito específico destinado a condução da saúde pública.

Primeiramente, o contexto histórico da saúde antes da instauração da reforma sanitária foi perante as amarras da ditadura, em que houve a repressão das manifestações populares, a abertura econômica ao capital estrangeiro atrelada ao congelamento dos salários e cassação do direito à greve. E, o sistema público de saúde vivia sob a dicotomia da ala previdenciária para o cuidado com a saúde individual dos trabalhadores, voltado primordialmente para as zonas urbanas que estavam sendo ocupadas pela expansão fabril, subsidiando os encargos da previdência $^{2}$.

Enquanto a saúde pública restava sob o controle do Ministério da Saúde (MS), norteada para as áreas rurais como forma de abarcar as esferas tidas como mais carentes da população, deixando o atendimento preventivo. A meta era expansão do setor privado, a contratação de companhias e cooperativas privadas de médicos para prestar serviços em formas de convênios. (ALMEIDA; GIOVANELLA, 2008).

Tal cenário é visto no período do governo militar como o marco que assinala a crise de recursos, materiais básicos e de atuação do Ministério da Saúde, em que pese os dados

\footnotetext{
${ }^{2}$ O governo de Getúlio Vargas incorporou o Institutos de Aposentadorias e Pensões ao Ministério do Trabalho, Industria e Comércio (MTIC) as caixas de aposentadorias e pesões (PAIVA; TEIXEIRA, 2014).
} 
orçamentários no âmbito da saúde da União terem caído de 2,21\% para 1,40\%, no período de 1968 até 1972. Concomitantemente, as Forças Armadas e o Ministério dos Transportes detinham respectivamente a destinação de $18 \%$ e $12 \%$ (BRAGA; PAULA, 1986).

Nesse diapasão, a avaliação internacional de diagnósticos apontava para o enfraquecimento da cobertura assistencial e a proliferação de doenças visivelmente associadas ao nível de pobreza da população, como as verminoses e as de disseminação hídrica, como apontava a Organização Pan-Americana da Saúde ${ }^{3}$.

Consequentemente, o cenário nacional era mal visto quanto ao enfrentamento sanitário, sujeitando o país a aplicação das táticas de medicina simplificada, como aquelas aplicadas nos países em desenvolvimento, a exemplo da política da República Popular da China - Médicos de Pés Descalços, apontando a atenção primária como método central para alcançar a meta internacional de "Saúde para todos no ano 2000", estruturada na Conferência de Alma-Ata (CUETO, 2004).

Contudo, apesar do cenário de repressão dos anos 70, o regime militar estatuiu - por meio da Lei no 6.229/75, o Sistema Nacional de Saúde que enquadraria as competências nas atuações de coordenação de vigilância epidemiológica em todo o país, com a responsabilidade de supervisão e vistoria sanitária quanto ao aporte coletivo. E, o mais importante, definia que o Sistema Único de Saúde deveria ser pautado na separação das sistemáticas preceptoras de recursos humanos e das carências do sistema de saúde.

Em tal caso, o Ministério da Educação e da Cultura ficaria incumbido da estruturação e formação educacional dos profissionais de nível superior, auxiliar e técnico das áreas de saúde, além de assumir os hospitais universitários e a responsabilidade de ditar as diretrizes das profissões que lidavam diretamente com a área. Todavia, a ausência de conexão entre o eixo de formação e a execução do conhecimento apreendido gerava dissonância quanto as necessidades epidemiológicas e de atenção ao povo (LAMPERT, 2002).

Sob essa perspectiva, o campo da saúde coletiva que indicava a atenção primária como fundamental para a estruturação de um sistema de saúde com produção de saber e aplicabilidade no território de práticas democráticas de cuidado, junto com outros atores das lutas trabalhistas, foram os principais fatores que deram início a Reforma Sanitária no Brasil com a imprescindibilidade de restauração da democracia no país.

\footnotetext{
${ }^{3}$ Essa constituí como a agência especializada em saúde no sistema interamericano, constituída também como escritório regional da Organização Mundial da Saúde (OMS). Disponível em: https://www.paho.org/pt/brasil/sobre-opasoms-brasil
} 
Em consequência dessas insatisfações e manifestações dos trabalhadores liberais, com o início dos anos 80 foi dado o ponta pé para a mudança das antigas discussões sobre a saúde, a exemplo do primeiro Simpósio sobre Política Nacional de Saúde da Câmara dos Deputados, tratando dos princípios que auxiliariam na reforma sanitária. Isto é, a universalidade do direito à saúde; a descentralização, hierarquização e regionalização do sistema de atendimento; a administração democrática e a urgência de integração da antiga dualidade do atendimento público e previdenciário (CEBES, 1980).

Entretanto, mesmo com o retorno da democracia com a carta constitucional de 1988, com a estruturação do Sistema Único de Saúde (SUS) e com a formulação da Lei Orgânica da Saúde, a crise econômico-financeira enfrentada na esfera pública provocara inseguranças e empecilhos de fincar infraestrutura palpável para o enfrentamento das doenças no nível territorial continental que o Brasil apresenta, medidas essas que não coadunavam com os interesses dos grupos empresariais que detinham forte poder político, acirrado mais ainda pela pungência das disparidades regionais.

Essas dessemelhanças ficaram evidentes no cenário social e econômico com a repercussão nos perfis epidemiológicos acarretados devido ao contexto de vida nas regiões, divergindo de acordo com o consumo de bens, de acesso à moradia digna, ao saneamento básico, apresentando como sequela o aumento da exposição aos riscos no espaço urbano.

Em detrimento disso, embora a ideia de transformação das condições de saúde e da própria forma de tratar a sociedade não tenha sido atingida, a reforma desencadeou o olhar crítico para as atividades desenvolvidas pelos órgãos da administração direta e autárquica, em vista de muitas das vezes os comandos não coadunarem com as diretrizes de pensamento da sistemática universal e integralizada (PAIM, 2008).

Dessa maneira, o planejamento sanitário muita das vezes desconsidera a heterogeneidade que secciona os cidadãos em camadas sociais com poderes aquisitivos, políticos e influências culturais diferentes, com apropriação do espaço urbano de forma singular e individualizada. Consequentemente, o apartheid sanitário é problema a ser solucionado na atual crise vivenciada nos centros urbanos, com o questionamento: como gerenciar o procedimento de atenção básica de sanitária enfrentando as desigualdades e o fracionamento do sistema de saúde?

Essa segmentação do sistema de saúde, instaurada independentemente da estruturação do Sistema Único de Saúde (SUS), exibe a urgência e fortalecimento das estratégias de atenção primária à saúde, com os níveis de regionalização e hierarquização condizentes com 
os perfis das cidades, como forma de combater o fracionamento da sistemática de atendimento e para fundamentar a os investimentos exigíveis no âmbito de rede pública, com aparatos seguros e com a qualidade necessária tanto para os usuário quanto para os profissionais que são formados para atingir o cuidado coletivo na sociedade.

\section{CUIDAdo COLETIVO: A SAÍdA ATRAVÉS dA ATENÇÃO BÁSICA À SAÚdE PARA A CONSECUÇÃO DO DIREITO À CIDADE SAUDÁVEL}

E, para o enfrentamento dessa crise sanitária que adentrou o séc. XXI, a saída pode estar disposta no aprimoramento da Atenção Primária à Saúde, incorporada no Brasil por meio da Política Nacional de Atenção Básica, no âmbito do Sistema Único de Saúde (SUS), que passou por revisões e amoldamentos às exigências constitucionais. Além da estruturação da Atenção Básica (AB) ao atendimento da porta de entrada do Sistema público de Saúde, por meio das Unidades Básicas de atendimento (UBS).

Nessa lógica, Política Nacional de Atenção Básica reexaminada e reciclada por meio da Portaria $\mathrm{n}^{\circ}$ 2.436, de21 de Setembro de 2017, determinando as linhas e condutas das diretrizes de cuidado, como versa no art. $2^{\circ}$ :

Art. 2o A Atenção Básica é o conjunto de ações de saúde individuais, familiares e coletivas que envolvem promoção, prevenção, proteção, diagnóstico, tratamento, reabilitação, redução de danos, cuidados paliativos e vigilância em saúde, desenvolvida por meio de práticas de cuidado integrado e gestão qualificada, realizada com equipe multiprofissional e dirigida à população em território definido, sobre as quais as equipes assumem responsabilidade sanitária (BRASIL, 2017).

Nessa conjuntura, a preparação dos profissionais de saúde e dos agentes administrativos que laboram na gestão pública do acesso à saúde deve ser instruída de acordo com a Lei de Diretrizes e Bases da Educação Nacional (LDB) - Lei no 12.796, de 4 de abril de 2013, para se qualificar não apenas para adentrar o mercado de trabalho, como também para que tenha capacidade de encarar o cuidado coletivo em forma de ações de identificação dos problemas da situação da saúde no território.

Esse cuidado coletivo como componente das Diretrizes Curriculares Nacionais dos cursos de Saúde serve como subsídio para o olhar intersetorial de aplicação das políticas públicas sanitárias e do atendimento básico, trabalhando as necessidades das cidades de acordo com diagnósticos das comunidades, do controle social e das hipossuficiências. 
Portanto, colocaria em prática o princípio doutrinário do SUS da integralidade que considera "as dimensões biológica, cultural e social do usuário, orienta políticas e ações de saúde capazes de atender as demandas e necessidades no acesso à rede de serviços" (FRACOLLI, 2011, p. 1136), apresentando atendimento humanizado e condizente com a realidade dos pacientes.

Nessa perspectiva, a coordenação da prática da atenção básica nos centros urbanos enseja a análise do ambiente citadino não especificamente por meio do território enquanto marco geográfico, mas o território enquanto processo. As interações e forma como ele se reproduz por meio das relações sociais que o constituem (LEFEBVRE, 2020).

Sendo assim, a visão da forma tático-operacional que as políticas de saúde seguem não reproduzem um estudo de caso de uma cidade perante uma gestão específica, não é a reprodução do olhar técnico municipal e sim o panorama sobre o espaço urbano do país, que detém particularidades de acordo com as regiões.

Diante disso, a forma de abarcar essas deficiências de estruturação procedimentais da Política de Saúde é estruturando-a nos eixos vertical e horizontal para elaboração e aplicação da governança. O eixo vertical que é centrado na concepção das políticas públicas para o âmbito nacional, com o gerenciamento do Sistema Único de Saúde (SUS) - regulamentado pela Lei $\mathrm{n}^{\circ}$ 8.080/90, continuaria com a aplicabilidade das garantias constitucionais referentes ao direito à saúde, construída por mediação dos instrumentos normativos (CONASEMS, 1990).

Enquanto o eixo horizontal reverberará sobre a atuação da política de saúde nas cidades e acerca das prováveis interferências devido as inomogeneidades de ocupação do espaço urbano e das conjunturas de vida dos habitantes. À vista disso, é analisada a aplicabilidade da política transversal, em que se faz necessária a comunicabilidade da hierarquia institucional federal com as diretrizes e especificações estaduais e municipais (PEDROSO; VIEIRA, 2009).

Tal metodologia compactua com a referência da Política Nacional de Humanização da atenção e gestão do Sistema Único de Saúde, que "aposta na inclusão de trabalhadores, usuários e gestores na produção e gestão do cuidado e dos processos de trabalho" (BRASIL, 2013, p. 4). Isto é, possuem o objetivo de amplificar o contato, a troca de conhecimento e comunicação entre os agentes para retirar a ideia de hierarquização isolada e dispare da realidade dos centros urbanos, pois os diversos saberes podem conduzir a aplicação da saúde com corresponsabilidade. 
Sendo assim, a lógica condizente a proteção, acesso e promoção da saúde aos cidadãos que habitam os distintos territórios são idealizadas em concordância com esses eixos. É feito o ajuste e enquadramento situacional da saúde nas cidades com a Política Nacional de Saúde, para suprir as dificuldades subjetivas enfrentadas em cada localidade do ente federativo para o alcance da gestão democrática da atenção básica.

Busca-se, assim, "articular a dimensão política com as instâncias de decisão sobre a produção, distribuição e organização assistencial, no espaço onde tais políticas se concretizam: os serviços locais de saúde" (BODSTEIN, 1993, p. 9). O exemplo de medidas complementares que podem auxiliar nessa gestão mais democrática são as oficinas de territorialização, que constituem procedimento estratégico de sistematização das informações dos grupos sociais de determinada localidade, examinando a situação de saúde e especializando as estratégias de tratamento.

Portanto, a prerrogativa é estruturar a partir da metodologia de ordenamento territorial e mapeamento das singularidades das localidades para desenvolver a atenção básica a saúde adequada, devido o Sistema Único de Saúde (SUS) ser um sistema público “fundamentado num projeto territorial descentralizado, hierarquizado e integrado regionalmente através das redes de atenção à saúde" (FARIA, 2020, p. 3). Não importando a localidade em que o paciente se encontre, ele deve ter o acesso à saúde nas redes regionalizadas.

Assim como determina a Agenda 2030, documento e compromisso firmado pelos líderes de 193 países, incluindo o Brasil, a tratativa foi coordenada pela Organização das Nações Unidas, mediante o Programa das Nações Unidas para o Desenvolvimento (PNUD), recepcionado pelo Poder Judiciário por meio do Conselho Nacional de Justiça, discorrendo sobre as metas e os objetivos especificamente no que concerne aos Objetivos de Desenvolvimento Sustentável (ODS) nº 3 e 11.

Em que tratam de assegurar vida saudável e promoção do bem-estar para todos os indivíduos e acesso as cidades mais seguras, resilientes e sustentáveis, respectivamente. Em consequência disso, reverbera na intenção de promoção das cidades mais saudáveis, alinhadas a consecução do direito à cidade. Sendo assim, a qualidade da vida urbana não deve ser considerada pela aura de livre escolha.

De acordo com o geógrafo David Harvey, o acesso ao direito à cidade é um dos direitos que não devem ser negligenciados aos cidadãos, pois antes de mudanças de cunho individual, a garantia é comum devido as transformações afetarem o poder coletivo de produção e estruturação da urbanização (HARVEY, 2003). Essa que já foi debatida para além 
da reprodução do território enquanto local físico, perpetrando na forma de reprodução das relações sociais.

Assim, o raciocínio da cidadania no elemento social coaduna com o status de promoção da lógica de igualdade na produção de vida e reconhece a necessidade de cuidar do direito à saúde como reconhecimento da valorização dos cidadãos, por meio do aprimoramento da Atenção Básica à Saúde (ABS), de forma universal e igualitária (MARSHALL, 2002).

Destarte, a Política Nacional de Atenção Básica (PNAB) poderá embasar de forma estratégica o enfrentamento da crise que se instaurou no atendimento do sistema público, reconhecendo as fragilidades de sociais em detrimento das desigualdades sociais e das problemáticas políticas que tem sido encaradas no atual cenário nacional.

O novo rumo poderá se amparar nas diretrizes da Agenda 2030 e no alcance das cidades saudáveis, com gestão democrática, participação popular e controle social, conduzindo a concepção ampliada de saúde. De modo que seja reconhecida como direito fundamental que "inclui a promoção da cidadania e o envolvimento criativo de organizações 'comunitárias' no planejamento e execução de ações intersetoriais dirigidas à melhoria das condições de vida e saúde, principalmente em áreas territoriais das grandes cidades" (TEIXEIRA, 2002, p. 90).

Em resumo, requererá o enfrentamento das desigualdades perante as camadas sociais, que reproduzem a ocupação no território de forma diferenciada, examinando os índices intraurbanos de mortalidade, riscos de exposição a contaminação e desenvolvimento das morbidades, como análise dos consequentes fenômenos das disparidades econômicas (SANTOS, 1994).

Parte-se da noção e mapeamento da constituição e ordenamento do espaço urbano, que indicará a carga histórica de reprodução no território determinante para a formação dos arquétipos de apropriação do trabalho, do tempo e dos locais, reverberando nas desigualdades de acesso à saúde para alcançar a forma mais adequada de garantir acesso universal de atenção básica a população, através do entendimento da sistemática do cuidado coletivo da saúde.

\section{CONCLUSÃO}


As proposições realizadas no presente trabalho tiveram como objetivo sugerir e convidar a refletir sobre novas formas de estruturar a Atenção Básica de Acesso à Saúde, revendo a reprodução das relações sociais na estruturação do ordenamento territorial, repercutindo principalmente na pauperização da mão de obra, ligada a abertura da economia no país aos estrangeiros, que fincaram fábricas e influenciaram na urbanização ou gentrificação, como preferir, dos centros urbanos.

Nesse sentido, foi necessário o olhar do território enquanto processo e expressão das relações sociais que se desenvolviam no Brasil, indo além do limite territorial e representando um espaço social de apropriação do solo que reproduzia várias desigualdades advindas das relações de produção.

Ademais, através da análise interseccional do histórico econômico, social e político de estruturação do atendimento da Saúde desde o período de crescimento dos centros urbanos, pode-se ver que a meta era o atendimento privado para suprir as demandas previdenciárias que surgiam no país com a chegada dos inúmeros trabalhadores as capitais, focando no cuidado individual desses.

Ao passo que a saúde pública ficava a margem da atenção do Ministério da Saúde e com decréscimo de investimentos que reverberaram devido aos períodos mais críticos de debilidade econômica, em que o sistema público de atendimento à saúde carecia de insumos, políticas públicas e mão de obra para enfrentar os problemas sanitários que eram notificados como doenças de "terceiro mundo", com disseminação e contaminação pelo acesso à água, que também não era salubre.

Perante tais adversidades e com a visão contextualizada das problemáticas pode-se observar que as incongruências políticas fortaleceram as reivindicações dos agentes envolvidos no cenário sanitário para propor uma reforma. Ela veio com o peso da luta pela redemocratização no país e devido a ausência de um aporte coletivo a ser reconhecido no bojo da Constituição Federal do período, referente ao rol dos direitos fundamentais.

Desse modo, através das proposições para o aprimoramento da formação do cuidado coletivo e da estruturação da atenção básica à saúde para o alcance das cidades saudáveis, o enfoque operacional seguiu baseado na gestão democrática e participativa com a sociedade, com os agentes de saúde e com os políticos, para a conquista e transformação no acesso primário a saúde.

Sendo assim, a interseccionalidade dos projetos pode apontar para o cumprimento das metas da Agenda 2030, promovendo a saúde, o direito à cidade e a recognição do arquétipo 
do que anteriormente eram as ações coletivas de saúde, instituindo uma visão de cuidado coletivo para a porta de entrada do sistema público de saúde. Em que os projetos técnicos e assistenciais supram as disparidades socioeconômicas que se instalaram frente a reprodução das relações sociais na ocupação do território.

Portanto, o artigo visa subsidiar o incentivo e expansão da escuta das reivindicações dos atores sociais que são os principais envolvidos e afetados pela negligência de estruturação das políticas públicas, para que eles se vejam representados pelo Plano Nacional de Melhoria do Acesso e da Qualidade da Atenção Básica (PMAQ). Diante disso, a carta democrática de 1988 ao elevar a saúde ao patamar de direito fundamental, reverbera a recognição deste dentro de não só atuação governamental, como também se configura como questão de Estado.

A setorização e dissociação das realidades vividas nas diversas regiões apresentaram por diversos anos a insuficiência de aplicação do papel principal da rede básica, essa que necessita de planejamento participativo.

\section{REFERENCIAS}

ALMEIDA, Patty Fidelis de; GIOVANELLA, Ligia. Avaliação em Atenção Básica à Saúde no Brasil: mapeamento e análise das pesquisas realizadas e/ou financiadas pelo Ministério da Saúde entre os anos de 2000 e 2006. Cadernos de Saúde Pública, v. 24, n. 8, p. 1727-1742, 2008.

ARANTES, Cássia Irene Spinelli et al. Cuidado coletivo na atenção primária em saúde: concepções de graduandos de enfermagem. Revista Enfermagem UERJ, v. 21, n. 6, 2013.

BAUMAN, Z ygmunt. Confiança e medo nas cidades. Rio de Janeiro: Jorge Zahar, 2010.

BODSTEIN, R. C. A. (Org.). Serviços locais de saúde: construção de atores e políticas. Rio de Janeiro: Relume-Dumará, 1993.

BRAGA, José Carlos de Souza; PAULA, Sergio Goes de. Saúde e previdência: estudos de política social. In: Saúde e previdência: estudos de política social. 2006.

BRASIL, Ministério da Saúde. Secretaria de Atenção à Saúde. Núcleo Técnico da Política Nacional de Humanização. Ambiência. 2. ed. Brasília, DF: Ministério da Saúde; 2013.

BRASIL. Lei $\mathbf{n}^{\mathbf{0}}$ 12.796, de 4 de abril de 2013. Aprova a Lei de Lei de Diretrizes e Bases da Educação Nacional. Disponível em: http://www.planalto.gov.br/ccivil_03/_ato20112014/2013/lei/112796.htm. Acesso em: 04 de maio de 2021.

BRASIL. Lei no 6.229, de 17 de julho de 1975. Cria o Sistema Nacional de Saúde. Brasília, DF, 1975. Disponível em: http://www.planalto.gov.br/ccivil_03/leis/16229.htm. Acesso em:03 de maio de 2021. 
Brasil. Ministério da Saúde. Portaria $\mathbf{n}^{\mathbf{0}}$ 2.436, de 21 de setembro de 2017. Aprova a Política Nacional de Atenção Básica, estabelecendo a revisão de diretrizes para a organização da Atenção Básica, no âmbito do Sistema Único de Saúde (SUS). Brasília, DF: Ministério da Saúde, 2017.

CEBES. A questão democrática na área da Saúde. Rio de Janeiro: Saúde Debate, n. 9, p. 11-13, 1980.

CONASEMS, Conselho Nacional de Secretários Municipais de Saúde. Sistema Único de Saúde: Lei $n^{\circ}$ 8.080 de 19 de setembro de 1990. Brasília: Conasems/Ministério da Saúde, 1990.

COUTINHO, Ronaldo; AHMED, Flávio. Cidade, direito e meio ambiente perspectivas críticas. Rio de Janeiro: Lumen Juris, 2011.

CUETO, Marcos. The origins of primary health care and selective primary health care. American journal of public health, v. 94, n. 11, 2004.

FARIA, Rivaldo Mauro de. A territorialização da Atenção Básica à Saúde do Sistema Único de Saúde do Brasil. Rio de Janeiro: Ciência saúde coletiva, v. 25, n. 11, p. 4521-4530, 2020.

FRACOLLI, Lislaine Aparecida et al. Conceito e prática da integralidade na Atenção Básica: a percepção das enfermeiras. São Paulo: Revista da Escola de Enfermagem da USP, v. 45, n. 5, p. 1135-1141, 2011.

HARVEY, David. The right to the city. International journal of urban and regional research, v. 27, n. 4, p. 939-941, 2003.

KOWARICK, L. A pobreza urbana. Paraná: Cadernos de Justiça e Paz, 1980.

KOWARICK, Lúcio. A espoliação urbana. 2 ed. Rio de Janeiro: Editora Paz e Terra, 1993.

LAMPERT, Jadete Barbosa. Tendências de mudanças na formação médica no Brasil. Tese de Doutorado em Saúde Pública. Escola Nacional de Saúde Pública Sérgio Arouca, Fundação Oswaldo Cruz. Rio de Janeiro, 2002.

LEFEBVRE, Henri; GOONEWARDENA, Kanishka. Space, difference, everyday life. New York: Routledge, 2008.

LEFEBVRE, Henri. La producción del espacio. Madrid: Capitán Swing Libros, 2020.

LEFEBVRE, Henri. O direito à cidade. São Paulo: Centauro, 2001.

MARSHALL, Thomas Humphrey. Cidadania e classe social: Coleção Leituras sobre a Cidadania. Brasília, Senado Federal, 2002. 
MELAZZO, E. S e GUIMARÃES, R. B. Ponto de partida: a desigualdade social e a definição da política urbana. In: MELAZZO, E. S. e GUIMARÃES, R. B. Exclusão social em cidades brasileiras. São Paulo: Ed. Unesp, 2010.

MENDES, Luís. Cidade pós-moderna, gentrificação e a produção social do espaço fragmentado. São Paulo: Cadernos Metrópole., v. 13, n. 26, p. 473-495, 2011.

MORAES, Antonio Carlos Robert. Território e história no Brasil. São Paulo: Annablume, 2005.

PAIM, Jairnilson Silva. Reforma sanitária brasileira: contribuição para a compreensão e crítica. Rio de Janeiro: Editora Fiocruz, 2008.

PAIVA, Carlos Henrique Assunção; TEIXEIRA, Luiz Antonio. Reforma sanitária e a criação do Sistema Único de Saúde: notas sobre contextos e autores. Manguinhos: História, Ciências, Saúde, 2014.

PEDROSO, Raquel Turci; VIEIRA, Maria Edna Moura. Humanização das práticas de saúde: transversalizar em defesa da vida. Botucatu: Interface, v. 13, supl. 1, p. 695-700, 2009.

RIBEIRO, Luiz César de Queiroz; SANTOS JÚNIOR, Orlando Alves dos. Globalização, fragmentação e reforma urbana. Portal Regional da BVS, p. 426-426,1994.

SANTOS, Milton. O espaço do cidadão. São Paulo: Nobel, 1988.

SANTOS, Milton; SILVEIRA, Maria Laura. O Brasil: território e sociedade no início do século XXI. São Paulo: Record, 2001.

SANTOS, Milton. A natureza do espaço: técnica e tempo, razão e emoção. São Paulo: Edusp, 2002.

SANTOS, Milton. Metamorfoses do espaço habitado. São Paulo: Hucitec, 1997.

TEIXEIRA, Elenaldo Celso. O papel das políticas públicas no desenvolvimento local e na transformação da realidade. Salvador: AATR, v. 200, 2002. 